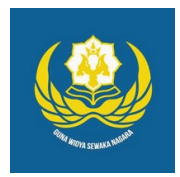

Jurnal Analogi Hukum

Journal Homepage: https://ejournal.warmadewa.ac.id/index.php/analogihukum

\title{
Ko-Eksistensi Hukum Negara dan Hukum Adat Bali Dalam Pengangkatan Anak (Studi di Desa Adat Lantangidung, Kecamatan Sukawati, Kabupaten Gianyar)
}

\author{
Ketut Rai Mahajony*, I Made Suwitra dan Diah Gayatri Sudibya
}

Fakultas Hukum, Universitas Warmadewa, Denpasar, Bali-Indonesia

*raimahajony@gmail.com

How To Cite:

Mahajony, K. R., Suwitra, I. M., \& Sudibya, D. G. (2021). Ko-Eksistensi Hukum Negara dan Hukum Adat Bali Dalam Pengangkatan Anak (Studi di Desa Adat Lantangidung, Kecamatan Sukawati, Kabupaten Gianyar). Jurnal Analogi Hukum. 3 (2). 245-250. Doi: https:// doi.org/10.22225/ah.3.2.2021.245-250

\begin{abstract}
Traditional Balinese marriages follow the male bloodline (patrilineal), so having a son is still the goal of a marriage. Adoption of children (sentana peperasan) is an option if the family has no children to continue the obligations towards the family and society. Several cases of adoption, such as in the case of adoption in Lantangidung Village, Gianyar Bali, were raised in this study as case studies. The problem raised is how legal the adoption of children is according to Balinese Customary Law and State Law and the position of adopted children in the family and society according to Balinese Customary Law. This research is expected to expand the legal knowledge of the community, especially regarding the combination of Balinese Customary Law and State Law in terms of adoption. An empirical approach is used to see the combination of Balinese Customary Law and State Law. The conclusion is that: the co-existence of Balinese customary law and state law in the implementation of adoption needs to be clarified in more detail with an easy-to-understand sequence of implementation so that the position of adopted children in the family and society is also strong.
\end{abstract}

Keywords: Adopted Children; Balinese Customary Law; State Law; Co-Existence.

Abstrak-Perkawinan Adat Bali mengikuti garis darah laki-laki (patrilineal), maka mempunyai anak laki masih menjadi tujuan sebuah perkawinan. Mengangkat anak (sentana peperasan) adalah sebuah pilihan jika keluarga tidak mempunyai keturunan untuk melanjutkan kewajiban terhadap keluarga dan masyarakat. Beberapa kasus pengangkatan anak seperti dalam kasus pengangkatan anak di Desa Lantangidung Gianyar Bali yang diangkat dalam penelitian ini sebagai studi kasus. Masalah yang diangkat adalah bagaimana sahnya pengangkatan anak secara Hukum Adat Bali maupun Hukum Negara serta kedudukan anak angkat dalam keluarga dan masyarakat menurut Hukum Adat Bali. Penelitian ini diharapkan dapat memperluas pengetahuan hukum masyarakat khususnya mengenai perpaduan Hukum Adat Bali dan Hukum Negara dalam hal pengangkatan anak. Pendekatan empiris dipakai guna melihat perpaduan Hukum Adat Bali dan Hukum Negara. Kesimpulan yang didapat bahwa: ko-eksistensi hukum adat Bali dan hukum negara dalam pelaksanaan pengangkatan anak perlu lebih diperjelas dengan lebih detail dengan urutan pelaksanaan yang mudah dipahami sehingga kedudukan anak angkat dalam keluarga dan masyarakat juga menjadi kuat.

Kata Kunci: Anak Angkat; Hukum Adat Bali; Hukum Negara; Ko-Eksistensi.

\section{Pendahuluan}

Salah satu tujuan perkawinan adalah memperoleh keturunan yang akan meneruskan keberlangsungan garis keturunan yang ada plus dalam kehidupan adat Bali juga untuk meneruskan kewajiban-kewajiban adat baik dalam lingkup keluarga maupun kemasyarakatan. Keluarga Hindu Bali yang menempati tanah adat (tanah AyDs) wajib mentaati segala ketentuan adat yang ada yang tentunya dilaksanakan oleh orang yang menempati tanah ayahan desa tersebut. Karena itu ketika sebuah keluarga yang menempati tanah ayahan desa tersebut tidak mempunyai keturunan, maka mengangkat anak adalah sebuah keniscayaan jika tidak ingin tanah dan rumah yang ditempatinya kembali menjadi milik desa adat. Tujuan lembaga mengangkat 
sentana ialah melanjutkan keturunan dari kepurusa, agar kemudian sesudah pengangkat meninggal, ada orang yang melakukan abenan mayatnya dan penghormatan pada rohnya dalam sanggah yang mengangkat (Panetje, 1986). Pengertian pengangkatan anak secara umum adalah suatu tindakan mengambil anak orang lain berdasarkan ketentuan-ketentuan hukum yang berlaku di masyarakat bersangkutan (Gosita, 1998), ataupun perbuatan hukum yang melepaskan anak itu dari pertalian kekeluargaan dengan orang tua sendiri yang memasukkan anak itu ke dalam keluarga bapak angkatnya sehingga anak itu sendiri seperti anak kandung (Soepomo, 2000).

Masyarakat Adat Bali menganut sistem patrilineal dalam perkawinan, maka adalah jamak bila keturunan laki-laki sangat diharapkan dalam sebuah keluarga Hindu Bali. Anak laki-laki penerus keturunan ini disebut dengan istilah sentana, dalam kamus Bali Indonesia, sentana berarti anak, keturunan atau anak angkat. Kalau mau membicarakan soal tata di masyarakat Bali, maka tidak akan berlebihan jika awig-awig itulah yang menonjol dan paling kedepan di masyarakat adat. AwigAwig yang lekat dengan soal-soal terdalam di segi lahir dan batin masyarakat adat, dan ini bukan soal yang ajaib sebab awig-awig itu mengatur secara horisontal hubungan masyarakat, juga mengatur hubungan vertikal masyarakat secara individu atau kelompok kepada Tuhan Yang Maha Esa (Sang Hyang Widi Wasa) (Artadi, 2017). Sentana (anak lelaki sulung) berasal dari kata santana $=$ anak keturunan (sebenarnya artinya adalah pelanjut, misalnya dari turunan), demikianlah dijelaskan oleh Vegel (Korn, 2013). Kata sentana dengan artinya yang demikian itu, memang umum dikenal dalam masyarakat Bali, tetapi secara khusus arti kata itu, adalah berkenaan dengan anak lelaki yang menggantikan ayahnya sebagai kepala keluarga dan dalam kedudukannya seperti itu (Korn, 2013). Tujuan dari adopsi terutama untuk melanjutkan keturunan. Berhubung dengan ini, akibat dari adopsi, adalah bahwa anak itu sepenuhnya menjadi anggota keluarga yang mengangkat, dan terutama dari sudut hukum waris, hubungan anak itu dengan orang tua yang sebenarnya diputuskan (Saragih, 1984).

Meskipun tampak sederhana namun dalam pelaksanaanya cukup memerlukan perencanaan dan persiapan matang agar tidak terjadi seperti kasus yang dipakai sebagai bahan kajian yaitu pengangkatan anak yang terjadi di Desa Adat Lantangidung Kecamatan Sukawati Kabupaten Gianyar antara tahun 1983 sampai tahun 1992, dimana seorang anak angkat batal diangkat sebagai anak alias dipecat, adik kandung sang anak angkat menghalangi dengan mengirimkan surat keberatan ke kantor camat saat mantan orang tua angkatnya ingin mengesahkan status anak angkatnya yang baru dengan mencari akta pengangkatan anak secara Hukum Negara. Kasus ini sudah mendapatkan putusan tetap Pengadilan Tinggi Denpasar dengan putusan nomor : 80/Pdt/1992/PT.Dps.

Masuknya permasalahan pengangkatan anak yang awalnya dilakukan secara adat Bali ke dalam lembaga pengadilan menunjukkan bahwa ada masalah dalam ko- eksistensi Hukum Negara dan Hukum Adat Bali dalam pengangkatan anak. Sehingga hal ini diangkat sebagai pokok permasalahan yaitu :

Bagaimana sahnya pengangkatan anak menurut Hukum Adat Bali dan Hukum Negara?

Bagaimana kedudukan anak angkat dalam keluarga dan masyarakat menurut hukum adat Bali?

\section{Metode}

Tipe penelitian yang akan dilakukan adalah penelitian hukum empiris karena kesenjangan / ketidak sesuaian antara Hukum Negara dan Hukum Adat Bali, dilengkapi dengan wawancara dengan para pihak yang berperkara dan melihat hasil putusan pengadilan. Pendekatan masalah yang digunakan adalah pendekatan perundang-undangan, pendekatan analitis dan pendekatan kasus.

Dalam penelitian ini digunakan sumber data sekunder yang disebut bahan hukum primer, yakni bahan hukum yang isinya mempunyai kekuatan hukum mengikat bagi setiap individu atau masyarakat, baik yang berasal dari peraturan Perundangan- Undangan maupun Putusan Pengadilan, antara lain : Undang-Undang Dasar Negara Republik Indonesia 1945, Kitab Undang-Undang Hukum Perdata, Undang-Undang nomor 1 tahun 1974 tentang Perkawinan, Peraturan Pemerintah Republik Indonesia Nomor 54 Tahun 2007 tentang Pelaksanaan Pengangkatan Anak, Surat Edaran Mahkamah Agung (SEMA) nomor 6 tahun 1983 tentang Penyempurnaan SEMA Nomor 2 tahun 1979 tentang Pemeriksaan Permohonan Pengesahan/Pengangkatan Anak, Peraturan Daerah Provinsi Bali nomor 3 tahun 2001 tentang Desa Pakraman yang telah diganti dengan Peraturan Daerah nomor 4 tahun 2019 tentang Desa Adat Bali, Putusan Pengadilan Negeri Gianyar 13/Pdt/G/1991/PN.Gir, Pengadilan Tinggi Denpasar dengan putusan 
nomor : 80/Pdt/1992/PT.Dps, Awig-Awig Desa Pakraman Lantangidung

Bahan hukum sekunder (bahan kepustakaan), yakni bahan-bahan yang erat hubungannya dengan bahan hukum primer dan dapat membantu menganalisis serta memahami bahan hukum primer, berupa buku-buku, hasil penelitian dan bahan pustaka lainnya yang berkaitan dengan penelitian.

Bahan hukum tersier, yakni bahan yang memberikan petunjuk maupun penjelasan terhadap bahan hukum primer dan sekunder, misalnya kamus, ensiklopedia, dan sebagainya.

Pengumpulan bahan hukum primer berupa dokumentasi dan bahan hukum sekunder dan tersier berupa pencatatan-pencatatan yang dilakukan dengan meneliti Peraturan Perundang -Undangan, Peraturan Pemerintah, Surat Edaran Mahkamah Agung, hukum adat Bali, AwigAwig Desa Adat dan berbagai literatur yang masih berlaku dan berkaitan dengan penelitian ini, kemudian dicatat dalam kertas lepas dengan mencantumkan Nama Pengarang, Judul Buku, Nama Penerbit, dan Tahun terbit. Bahan data primer berupa observasi lapangan dan wawancara dengan responden yaitu pihak penggugat dan pihak tergugat.

\section{Hasil dan Pembahasan}

Sahnya Pengangkatan Anak Menurut Hukum Adat Bali dan Hukum Negara Pengangkatan anak diatur dalam awig-awig Desa Adat masing-masing, dalam awig-awig Desa Adat Lantangidung diatur dalam pawos 57 sampai 59.

Pawos 57 (pasal 57) ayat 1 menyebutkan bahwa keturunan itu ada dua macam yaitu keturunan biologis dan anak angkat. Ayat 4 menyebutkan bahwa jika dalam perkawinan tersebut terjadi hal yang kurang berkenan yaitu tidak memperoleh keturunan, diperbolehkan mengangkat anak dengan disaksikan oleh yang berwenang dan upacara tertentu, anak tersebut disebut sentana paperasan (anak angkat).

Pawos 58 (pasal 58) ayat 1 menyebutkan bahwa dalam hal mengangkat anak harus sesuai peraturan yang ada dengan biaya tertentu dengan saksi yang berwenang dan upacara agama Hindu Bali. Ayat 2 menerangkan tentang krama yang akan mengangkat anak wajib melaporkan kepada Jro Bendesa (Ketua Adat Desa) dan yang berwenang setidaknya dalam 3 bulan (1 bulan Bali sekitar 35 hari, jadi selama 105 hari) sebelum upacara pengangkatan anak. Ayat 3 menjelaskan tentang kewajiban Bendesa yang diwakili oleh Kelihan Banjar (Kepala
Adat banjar) mengumumkan kepada krama, bilamana ada yang kurang setuju tentang pengangkatan anak tersebut agar melapor kepada Bendesa setidaknya sebelum masa 2 minggu (14 hari) sebelum upacara pamerasan. Ayat 4 menjelaskan tentang kewajiban pengurus Desa segera berembug dan memberikan keputusan sesuai peraturan/awigawig. Ayat 5 menyebutkan bahwa jika syarat pengangkatan anak tidak sesuai seperti di atas, Prajuru berhak menunda krama yang akan melaksanakan upacara pengangkatan anak dan memberikan tuntunan agar permasalahan yang ada diselesaikan terlebih dahulu.

Pawos 59 (pasal 59) ayat 1 menjelaskan tentang sahnya pengangkatan anak apabila dilaksanakan upacara Widhi Widana pamerasan (upacara agama Hindu Bali tentang pengangkatan anak), disaksikan untuk kemudian disahkan oleh Prajuru Desa (pengurus desa), diumumkan ke seluruh Desa Adat. Jelaslah bahwa seorang anak dianggap sah menjadi anak angkat jika sudah melewati upacara pamerasan, sebuah upacara sakral yang menjadi penentu sah tidaknya pengangkatan anak. Upacaranya disebut pamerasan, yang diangkat sebagai anak disebut anak paperasan. Ayat 2 menjelaskan bahwa yang berhak diangkat sebagai anak adalah orang yang beragama Hindu yang secara garis keturunan berada di bawah level keluarga yang mengangkat (adik, anak, ponakan, cucu, dan seterusnya), asal anak tersebut dari garis keturunan laki-laki (purusa) atau berlaku sebagai laki-laki, namun bila tidak ada, boleh dari garis keturunan perempuan (predana), jika juga tidak ada dari garis keturunan perempuan, maka boleh siapa saja, tetap diutamakan dari garis keturunan purusa ( garis keturunan lakilaki), calon anak angkat boleh juga berasal dari asal muasal keluarga yang satu kelompok pemujaan ( satu sanggah paibon) atau satu klan dadia atau yang lainnya dan tetap harus beragama Hindu. Ayat 3 menyebutkan bahwa tidak diperbolehkan mengangkat anak lebih dari satu orang. Hal ini karena adat Bali memerlukan hanya memerlukan satu anak (keluarga) untuk menjalankan segala kewajiban desa adat.

Secara garis singkat dapat dijelaskan bahwa menurut hukum adat Bali, hal paling menentukan sah tidaknya pengangkatan anak adalah adanya upacara peperasan dengan disaksikan dan disahkan oleh pengurus desa adat yaitu Jro Bendesa beserta unsur-unsur pemerintahan desa adat lainnya serta keluarga kedua pihak krama sekitar. Dalam kasus di Desa Adat Lantangidung ini, sebagian prasyarat 
Hukum Adat Bali sudah dilaksanakan antara lain pengumuman dalam paruman adat sampai

3 kali tanpa penolakan namun upacara peperasan IKS sebagai anak angkat oleh IWR sebagai orang tua angkat sebagai prasyarat utama belum dilaksanakan, keburu terjadi disharmoni hubungan orang tua angkat dan anak angkat juga antara keluarga orang tua angkat dan keluarga anak angkat.

Dari hasil wawancara dengan keluarga mantan anak angkat, I Wayan Sujana yang merupakan adik kandung IKS mantan anak angkat : IKS diangkat setelah perkawinan mekalan kalan (perkawinan adat Bali tahap 1 dengan dihadiri saudara dekat) hubungan dengan ayah angkat adalah satu sanggah gede (dadia). Saat duduk di sanggah, bape IWR bercerita, karena dia sudah tua dan tak mampu ngayahin banjar, terus siapa yang harus saya cari, memang kesini pantasnya, siapa yang bisa ikut sama saya ke rumah selatan (rumah IWR). Karena IWS mengurus rumah tua dan hanya bersaudara purusa berdua dengan kakaknya (IKS), otomatis sang kakaklah yang kemudian diangkat anak oleh IWR.

Karena saat itu semua serba gampang, cuma lapor klian saja, tidak ada bukti tertulis dan upacara pamerasan, cuma ada upacara mesakapan (perkawinan adat Bali tahap 2 upacara lebih besar dengan undangan saudara yang lebih luas) di rumah IWR, ada fotofotonya, sudah diserahkan ke pengadilan, entah dimana sekarang foto itu karena tidak pakai pengacara. Kemudian ada pihak ketiga masuk memperkeruh suasana, sehingga IKS yang sudah pernah diangkat anak dibenci. Pihak ketiga ini kemudian menyodorkan anaknya untuk diangkat.

Hubungan kekeluargaan anak angkat baru (IND) dengan ayah angkat (IWR) adalah IND adalah pertalian keluarga dari pihak istri IWR (predana). IND adalah anak dari adik istri IWR (NKR). Sedang pertalian keluarga dari kakak IWS adalah dari pihak laki (purusa) yaitu IWR sendiri. Hubungan dari persaudaraan satu sanggah gede yang tidak boleh putus. Akhirnya IKS diusir dari rumah itu. Padahal kewajiban sebagai anak sudah dipenuhi, misal IWR masuk rumah sakit, IWS yang urus. Saat masuk Rumah Sakit Manuaba bahkan IWS yang membersihkan sakitnya berupa bengkak di perut yang sangat bau, keluarga anak angkat baru (IND) tak ada yang mau kerjakan.

Namun esok harinya ketika dijenguk, IWR sudah tak ada di kamar. Dicari di rumahnya tak ada, IWR disembunyikan di rumah seorang dukun. Isunya bahwa IWR sakit karena ilmu hitam dari keluarga IWS, dia dikirim black magic karena keluarga IWS menunggu matinya IWR dan istri untuk mendapatkan harta benda IWR. Begitu cerita istri IWR di masyarakat.

Wawancara dengan I Wayan Regeg, mantan ayah angkat : Selama diangkat anak IKS tidak tinggal di rumah orang tua barunya namun lebih sering di rumah asalnya. Maka terjadilah masalah internal keluarga karena ada tidak cocokan, sehingga IKS dipulangkan ke rumah asalnya.

Wawancara dengan I Nyoman Dira, anak angkat yang menggantikan IKS : Permasalahan karena mengangkat anak yang sudah berkeluarga yang tidak dibenarkan oleh awigawig Desa Adat Lantangidung sehingga kena pamidanda batu-batu (denda berupa benda biasanya beras dan sejumlah uang) dan kena ayahan desa di dua tempat, yaitu di rumah asal maupun di rumah orang tua angkat. Setelah berjalan sekian lama sejak diumumkan di banjar, IKS memang diumumkan diangkat anak oleh IWR namun IKS tidak terlalu sering tinggal di rumah orang tua angkatnya. Ditambah dengan permasalahan internal, masalah keluarga yang tidak ada kecocokan, akhirnya IKS dipecat sebagai anak angkat. IKS sendiri tidak berkeberatan, namun adiknya IKS yang berkeberatan. Karena permasalahan ini, Desa Adat Lantangidung tidak berani memutuskan, maka disarankan masalah ini dibawa ke Pengadilan. Lalu proses Pengadilan Negeri Gianyar, ada dua proses yaitu memecat IKS dan mengangkat IND sebagai anak angkat IWR yang baru. Di Pengadilan Negeri Gianyar IWR, IKR (istri IWR) dan IND dipihak penuntut dan pihak yang dituntut IKS. Pihak penuntut memenangkan perkara di Pengadilan Negeri Gianyar, IKS lanjut banding ke Pengadilan Tinggi Denpasar namun lagi lagi kalah dan Pengadilan Tinggi Denpasar menguatkan semua keputusan Pengadilan Negeri Gianyar.

Dalam hukum negara persyaratan sahnya pengangkatan anak diatur dalam beberapa peraturan pemerintah yang satu sama lain saling terkait. Undang-Undang nomor 23 tahun 2003 tentang Perlindungan Anak, Peraturan Pemerintah nomor 54 tahun 2007 tentang Pelaksanaan Pengangkatan Anak, Peraturan Menteri Sosial Republik Indonesia nomor 110/ HUK/2009 tentang Persyaratan Pengangkatan Anak adalah berbagai hukum negara yang mengatur dan saling melengkapi tentang pengangkatan anak.

Beberapa syarat dalam pengangkatan anak 
tertuang dalam Peraturan Pemerintah nomor 54 tahun 2007 tentang Pelaksanaan Pengangkatan Anak dan Peraturan Menteri Sosial Republik Indonesia nomor 110/HUK/2009 tentang Persyaratan Pengangkatan Anak, terdapat istilah CAA (Calon Anak Angkat) dan COTA (Calon Orang Tua Angkat).

Beberapa pasal yang relevan buat dibahas dalam Peraturan Pemerintah nomor 54 tahun 2007 tentang Pelaksanaan Pengangkatan Anak, pasal 12 sama dengan pasal 4 Peraturan Menteri Sosial Republik Indonesia nomor 110/ HUK/2009 tentang Persyaratan Pengangkatan Anak di antara Persyaratan CAA, pasal 4, yang berisi syarat material CAA yaitu : a. Anak yang belum berusia 18 tahun. Pasal 12 Peraturan Pemerintah nomor 54 tahun 2007 tentang Pelaksanaan Pengangkatan Anak sama dengan pasal 7 Peraturan Menteri Sosial Republik Indonesia nomor 110/HUK/2009 tentang Persyaratan Pengangkatan Anak, Persyaratan COTA antara lain : b. Berumur paling rendah 30 tahun dan paling tinggi 55 tahun; c. Beragama sama dengan agama CAA. Syaratsyarat lainnya cenderung mudah dipenuhi dan tidak berpotensi berbeda dengan syarat dalam Hukum Adat Bali. Bila syarat terpenuhi maka pengesahan pengangkatan anak dengan mengajukan surat ke Kantor Kepala Desa, Camat sampai ke Pengadilan guna mendapatkan Penetapan Pengadilan. Ketika penetapan Pengadilan diperoleh maka sah lah sudah pengangkatan anak oleh orang tua angkat secara Hukum Negara. Hukum Negara dalam hal pengangkatan anak pada umumnya harus mengikuti prosedur yang telah digariskan dalam SEMA No. 2 Tahun 1979, penetapan lewat Pengadilan Negeri setempat

Dari kutipan duduk perkara dalam berkas Keputusan Pengadilan Tinggi Denpasar nomor 80/Pdt/1992/PT.Dps : 12. Bahwa dengan demikian lalu Bapak Camat mengeluarkan surat siaran yang aslinya ditujukan kepada Bapak Bupati Kepala Daerah Tingkat II Gianyar dan tembusannya antara lain kepada Bapak Ketua Pengadilan Negeri Gianyar, para Camat Seluruh Kabupaten Gianyar, Kepala Desa seluruh Kecamatan Sukawati, dan Kepala Dusun seluruh Desa Sukawati, dengan suratnya tertanggal 19 Juli 1990, No. 474.11/472/Pem1990 yang isinya : " Barang siapa yang berkeberatan tentang pengangkatan anak atas diri Penggugat-3 oleh Penggugat-1 dan Penggugat-2 agar dalam tenggang waktu 3 bulan terhitung sejak tanggal surat siaran dimaksud mengajukan gugatan ke Pengadilan Negeri Gianyar, dan bila dalam tempo 3 bulan tidak ada gugatan ke Pengadilan maka ---akta tersebut akan disahkan ; 13.Bahwa atas siaran itu sampai tanggal 9 November 1990 tidak ada orang yang mengajukan gugatan ke Pengadilan Negeri Gianyar ; 14.Bahwa oleh karena itu para Penggugat menghadap lagi ke Kantor Camat Sukawati dengan maksud memohon penyelesaian akta pengangkatan anak, namun secara tiba-tiba Bapak Camat tidak berani membuatkan akte tersebut dengan alasan tergugat menyatakan keberatan atas pengangkatan diri penggugat-3 oleh Penggugat1 dan Penggugat-2, yang mana keberatannya dinyatakan dengan surat tertanggal 7 Desember 1990 dan tidak berbentuk gugatan. Dari kutipan duduk perkara nomor 12, 13 dan 14 tersebut dapat dipetik sebuah kesimpulan bahwa Pejabat Camat tidak berani tegas menolak surat keberatan yang masuk meskipun sudah melewati batas tempo 3 bulan sejak diterbitkan siaran pengangkatan anak. Jika saja ada ketegasan sikap pejabat Camat, maka kasus gugatan Pengadilan ini tidak akan pernah terjadi.

Kedudukan Anak Angkat Dalam Keluarga dan Masyarakat Menurut Hukum Adat Bali Jika seorang anak sudah sah secara adat Bali masuk dalam sebuah keluarga, semestinya kedudukan sang anak angkat menjadi laiknya kedudukan anak kandung. Sang anak, bila telah dewasa berhak mewakili orang tua angkatnya dalam setiap kegiatan adat maupun dalam rapat-rapat adat yang memerlukan keputusan keluarga. Meskipun tampak mudah, dalam prakteknya sering terjadi gesekan-gesekan yang berujung pada perselisihan. Anak angkat yang sudah lebur menyatu dalam keluarga angkatnya biasanya tidak akan mendapatkan banyak masalah karena sistem kekerabatan yang erat dalam kehidupan berkeluarga. Adat Bali biasanya sangat fleksibel ketika para pihak yang terlibat sudah mampu menunjukkan kebersamaan dan kerukunan, semua hal umumnya bisa diselesaikan dengan musyawarah.

Disharmoni inilah yang terjadi antara keluarga IKS sebagai anak angkat dan keluarga IWR sebagai orang tua angkat. Ketergesaan dalam pengangkatan anak yang berujung pada kekisruhan di kemudian hari sampai akhirnya masuk ke Pengadilan Negeri Gianyar.

\section{Simpulan}

Sahnya pengangkatan anak menurut Hukum Adat Bali dan Hukum Negara masih ada ketidaksesuaian dan perlu ketegasan pejabat yang berwenang dalam penerapannya. Hukum Adat Bali tidak mensyaratkan umur sedang Hukum Negara maksimal 18 tahun contohnya. 
Syarat utama sahnya pengangkatan anak secara Hukum Adat Bali adalah upacara pamarasan, jika tidak dilaksanakan maka Prajuru Adat harus mengambil tindakan seperti peneguran orang tua angkat sampai membatalkan pengangkatan anak. Begitupun pejabat Negara dalam mengambil tegas seperti ketika masa sanggah sudah lewat batas waktu, harus berani menolak surat keberatan.

Kedudukan anak angkat dalam keluarga dan masyarakat menurut Hukum Adat Bali setara dengan anak kandung. Dengan masuknya anak angkat dalam sebuah keluarga diharapkan membawa kesejukan dan harapan utamanya dari keluarga orang tua angkat bahwa ada yang meneruskan hak dan kewajiban di keluarga dan masyarakat, namun dengan terjadinya disharmoni hubungan kekeluargaan antara anak angkat dan bapak angkat menjadi faktor utama perpecahan, baik antara dalam lingkup keluarga kecil anak angkat dan orang tua angkat sampai lingkup keluarga besarnya. Persiapan yang kurang matang secara fisik dan mental menjadi penyebab utamanya.

\section{Daftar Pustaka}

Artadi, I. K. (2017) Hukum Adat Bali dengan aneka masalahnya. Denpasar: Pustaka Bali Post

Gosita, A. (1998). Masalah Perlindungan Anak. Jakarta: Akademi Pressindo.

Korn, V. E. (2013). Bentuk-Bentuk Sentana menurut Hukum Adat Bali Masa Kolonial. Denpasar: Udayana University Press.

Panetje, G. (1989). Aneka Catatan Tentang Hukum Adat Bali. Denpasar: Guna Agung.

Soepomo, R. (2000). Bab-bab Tentang Hukum Adat. Jakarta: Pradnya Paramita.

Saragih, D. (1984). Pengantar Hukum Adat Indonesia. Bandung: Tarsito. 